\title{
Molecular phylogeny of the Bactrian camel based on mitochondrial Cytochrome b gene sequences
}

\author{
L. Ming ${ }^{1}$, L. Yi ${ }^{1}$, FC. Guo ${ }^{1}$, S. Siriguleng ${ }^{2,3}$ and J. Jirimutu ${ }^{1,2}$ \\ ${ }^{1}$ Key Laboratory of Dairy Biotechnology and Bioengineering, \\ Ministry of Education, College of Food Science and Engineering, \\ Inner Mongolia Agricultural University, Hohhot, Inner Mongolia, China \\ ${ }^{2}$ Camel Research Institute of Inner Mongolia, Alashan, Inner Mongolia, China \\ ${ }^{3}$ College of Veterinary Medicine, Inner Mongolia Agricultural University, \\ Hohhot, Inner Mongolia, China \\ Corresponding author: J. Jirimutu \\ E-mail: yeluotuo1999@vip.163.com
}

Genet. Mol. Res. 15 (3): gmr. 15038983

Received July 21, 2016

Accepted August 1, 2016

Published September 19, 2016

DOI http://dx.doi.org/10.4238/gmr.15038983

Copyright (C) 2016 The Authors. This is an open-access article distributed under the terms of the Creative Commons Attribution ShareAlike (CC BY-SA) 4.0 License

\begin{abstract}
The Bactrian camel is an important domesticated animal providing milk, meat, and other products in desert countries. In this study, 111 individuals representing 11 domestic Bactrian camel breeds from China, Mongolia, Russia, and one wild Bactrian camel group from Mongolia were selected for the preparation of mitochondrial DNA. The 1140-bp fragments of the cytochrome b gene $(C y t b)$ were amplified by polymerase chain reaction and sequenced directly. Sequences of the 92 domestic and 19 wild Bactrian camel samples were analyzed with DNASTAR, and a phylogenic tree was constructed using MEGA. The analysis revealed sixteen haplotypes among the samples that were divided into two haplogroups: a domestic haplogroup (H1-H13, H15,
\end{abstract}


and H16) and a wild haplogroup (H14). Haplotype diversity values were from 0.356 in the HosZogdort, to 0.889 in the Sunit Bactrian camel breed. The Sunit breed displayed the highest nucleotide diversity value (0.00115), and the HosZogdort breed had the lowest value (0.00031). All domestic Bactrian camels formed a single monophyletic lineage that is the sister group to wild Bactrian camels, a finding consistent with a single domestication event and independent maternal inheritance since domestication. In addition, the most common mitochondrial haplotypes (H1, H3, and H4) were shared between Chinese, Mongolian, and Russian domestic Bactrian camels, which indicated that there was no distinguishing geographic structure among the domestic breeds from these three regions. These findings provide important insights into patterns of relatedness among Bactrian camels from the Chinese, Mongolian, and Russian regions.

Key words: Cytochrome b gene (Cytb); Domestic Bactrian camel; Wild Bactrian camel; Bactrian camel breed; Haplotype;

Phylogenetic tree

\section{INTRODUCTION}

The Bactrian camel, also known as the two-humped camel, is uniquely adapted to hot and arid environments (Schwartz, 1992). Bactrian camels can provide a range of products and services, including milk, meat, wool, and blood, to the people who inhabit cold-arid and semi-arid desert regions (Groeneveld et al., 2010), which makes the Bactrian camel one of the most useful animals that humans have ever domesticated. In addition, scholars believe that the Bactrian camel made a great contribution to transportation on the Silk Road and could be portrayed as a bridge between the Eastern and Western cultures (Potts, 2005). This has enhanced the cultural and economic development of human societies (Ji et al., 2009a).

Bactrian camels include the domestic Bactrian camel (Camelus bactrianus) and the wild Bactrian camel (Camelus ferus). The domestic Bactrian camel is mainly distributed in central Asia and surrounding cooler areas (Ji et al., 2009a). Extant populations of the wild Bactrian camel are mainly distributed in the regions of the Gobi and Taklamakan Deserts of Mongolia and Xinjiang.

Mitochondrial DNA (mtDNA) has advantages for phylogenetic analysis, including its simple structure, small molecular weight, maternal inheritance, rare recombination, and high mutation rate compared with many nuclear markers. As a molecular marker, these characteristics of mtDNA sequences have been very important for studies of molecular evolution over past decades (Quan et al., 2000; He et al., 2009; Chuluunbat, et al., 2014). The cytochrome b gene $(C y t b)$ in the mtDNA genome is an important protein-encoding gene for studies of phylogenetic evolution and species classification (Johns and Avise, 1998; Li et al., 2005; Zhong et al., 2014). Thus far, the genetic diversity of different breeds of Bactrian camels from China, Mongolia, and Russia have never been characterized based on the Cytb gene, and only a partial survey of the breeds in China have been reported (Quan et al., 2000). Therefore, in this study, we collected samples from seven representative Bactrian camel breeds (Alxa,

Genetics and Molecular Research 15 (3): gmr.15038983 
Gobi Red, Qinghai, Mulei, Zhungeer, Tarim, and Sunit Bactrian camel) from China, three representative breeds (Galbiin Gobiin Ulaan camel, HosZogdort camel and Haniin Hetsiin Huren camel) from Mongolia, and one representative breed (Kalmyk Bactrian camel) from Russia; wild Bactrian camel samples were also collected from Mongolia. We analyzed sequence divergence and phylogenetic relationships based on the Cytb gene to discuss the genetic diversity and evolutionary relationships among these domestic Bactrian camel breeds and one wild Bactrian camel group.

\section{MATERIAL AND METHODS}

\section{Sample collection and DNA extraction}

Whole blood samples from 92 domestic Bactrian camels (C. bactrianus) representing 11 domestic breeds were collected from Bactrian camel breeding villages belonging to three Chinese provinces (Inner Mongolia, Xinjiang, and Qinghai), three regions in Mongolia (Hanbogd soum, Mandal-Ovoo soum, and Tugrug soum), and one region in Russia (Astrakhan City) (Figure 1). Ear tissue samples from 19 wild Bactrian camels (C. ferus) were collected from Gobi Altai in Mongolia (Figure 1). All blood samples were stored at $-70^{\circ} \mathrm{C}$. Total genomic DNA was extracted from blood or ear tissue using the standard phenol-chloroform extraction method described by Chengiia (Cheng et al., 2009). Detailed information of each Bactrian camel breed's name, geographic distribution, and sample size is provided in Table 1.

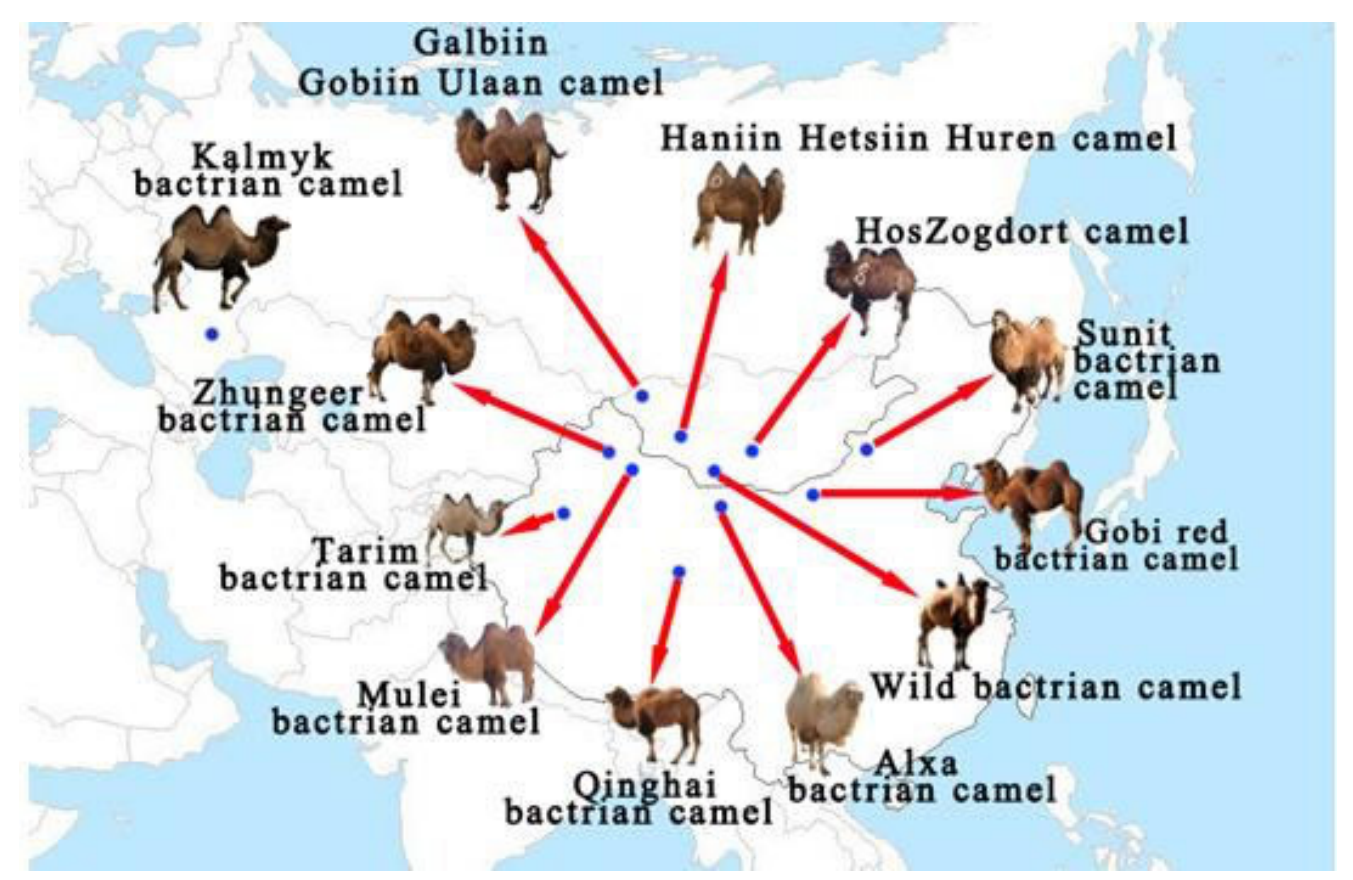

Figure 1. Geographic distribution of the 11 domestic Bactrian camel breeds and 1 wild Bactrian camel group analyzed in this study.

Genetics and Molecular Research 15 (3): gmr.15038983 
Table 1. Breed name, geographic distribution, collection of sample size, number of haplotypes, haplotype diversity, and nucleotide diversity for each different breed of Bactrian camel used in our study.

\begin{tabular}{l|l|c|c|c|c}
\hline Bactrian camel breed & Geographic distribution & Number of individuals & Number of haplotypes & Haplotype diversity & Nucleotide diversity $/ 10^{-2}$ \\
\hline Alxa & China, Inner Mongolia & 10 & 4 & 0.644 & 0.066 \\
\hline Gobi Red & China, Inner Mongolia & 10 & 4 & 0.644 & 0.08 \\
\hline Sunit & China, Inner Mongolia & 10 & 6 & 0.533 & 0 \\
\hline QingHai & China, Qinghai & 10 & 4 & 0.400 & 0.115 \\
\hline Zhungeer & China, Xinjiang & 5 & 2 & 0.600 & 0.035 \\
\hline Tarim & China, Xinjiang & 5 & 3 & 0.800 & 0.105 \\
\hline MuLei & China, Xinjiang & 5 & 4 & 0.643 & 0.105 \\
\hline Galbiin Gobiin Ulaan & Mongolia, Hanbogd soum & 8 & 6 & 0.778 & 0.066 \\
\hline Haniin Hetsiin Huren & Mongolia, Mandal-Ovoo soum & 10 & 2 & 0.356 & 0.088 \\
\hline HosZogdort & Mongolia, Tugrug soum & 10 & 3 & 0.667 & 0.031 \\
\hline Kalmyk & Russia, Astrakhan & 9 & 1 & - & 0.068 \\
\hline Wild & Mongolia, Gobi Altai & 19 & & & - \\
\hline
\end{tabular}

PCR amplification and product sequencing.

Polymerase chain reaction (PCR) primers for the amplification of the Cytb gene were designed by Zhang et al. (2008): forward 5'-ATG ACAAAC ATC CGAAAT CAC ACC-3' and reverse 5'-TCT TCA TTT TAG GAT ACG GTT TTC A-3'. The primers were designed using Primer 5.0 software and synthesized by Shanghai Sangon Biological Engineering Technology and Service Company (Shanghai, China). PCR amplification was implemented in a $50 \mu \mathrm{L}$ reaction mixture comprising $5 \mu \mathrm{L} 10 \mathrm{X}$ reaction buffer, $1 \mu \mathrm{L} 10 \mathrm{mM}$ dNTPs, $1 \mu \mathrm{L}$ of each primer $(10 \mu \mathrm{M}), 1.25 \mathrm{U}$ Taq DNA polymerase (TaKaRa Biosystems, Tokyo, Japan), and approximately $200 \mathrm{ng}$ template (the genomic DNA of each sample that was used as a template for PCR). The PCR mixture was subjected to the following conditions: denaturation for $5 \mathrm{~min}$ at $95^{\circ} \mathrm{C}$, followed by 32 cycles of $60 \mathrm{~s}$ at $94^{\circ} \mathrm{C}, 60 \mathrm{~s}$ at $52^{\circ} \mathrm{C}, 90 \mathrm{~s}$ at $72^{\circ} \mathrm{C}$, and finally annealing for $10 \mathrm{~min}$ at $72^{\circ} \mathrm{C}$. The PCR products were identified by agarose-gel electrophoresis, and DNA sequencing was performed on an ABI $3730 \mathrm{xl}$ DNA sequencer according to the manufacturer instructions.

\section{Data analysis}

Multiple alignments of nucleotide sequences were performed using Clustal W (Thompson et al., 1994), with variation sites deleted from the alignments. Indices of population diversity contained nucleotide diversity, haplotype diversity, and the number of haplotypes to be calculated using the DnaSP 5.0 software (Rozas et al., 2003). The phylogenetic tree was constructed from aligned sequences using the Unweighted Pair Group Method with Arithmetic Mean (UPGMA) (Sokal and Michener, 1958; Atteson, 1999) in the MEGA 5.1 software (Kumar et al., 2001). The Dromedary camel (Camelus dromedarius) was used as the outgroup.

\section{RESULTS}

\section{Analysis of nucleotide sequences}

After sequencing of the PCR products, 1140 nucleotides were determined in Cytb gene sequences of all 111 samples. The average contents of T, A, G, and C were 27.77, 28.96, 15.07 , and $28.20 \%$, respectively, which shows that the GC content (43.27\%) was less than the AT content (56.73\%). In this study, we detected only nucleotide substitutions, and no deletions 
or insertion mutations were observed. Among the 16 different haplotypes identified from the 111 Cytb sequences, we identified 17 variable sites (16 transitions and 1 transversion) (Table 2).

Table 2. Variation sites of the Cytb gene of wild and domestic Bactrian camels from Mongolia, China, and Russia.

\begin{tabular}{|c|c|c|c|c|c|c|c|c|c|c|c|c|c|c|c|c|c|c|}
\hline Haplotype & Number of individuals & $\begin{array}{l}1 \\
2 \\
8\end{array}$ & $\begin{array}{l}2 \\
1 \\
4\end{array}$ & $\begin{array}{l}4 \\
6 \\
3\end{array}$ & $\begin{array}{l}4 \\
7 \\
2\end{array}$ & $\begin{array}{l}4 \\
9 \\
2\end{array}$ & $\begin{array}{l}5 \\
2 \\
5\end{array}$ & $\begin{array}{l}5 \\
5 \\
3\end{array}$ & $\begin{array}{l}5 \\
7 \\
0\end{array}$ & $\begin{array}{l}6 \\
1 \\
8\end{array}$ & $\begin{array}{l}7 \\
0 \\
9\end{array}$ & $\begin{array}{l}7 \\
1 \\
1\end{array}$ & $\begin{array}{l}7 \\
1 \\
4\end{array}$ & $\begin{array}{l}7 \\
2 \\
3\end{array}$ & $\begin{array}{l}7 \\
3 \\
0\end{array}$ & $\begin{array}{l}8 \\
1 \\
9\end{array}$ & $\begin{array}{l}8 \\
2 \\
3\end{array}$ & $\begin{array}{l}8 \\
3 \\
4\end{array}$ \\
\hline H1 & 52 & $\mathrm{~T}$ & $\mathrm{G}$ & $\mathrm{T}$ & A & $\mathrm{T}$ & $\mathrm{C}$ & $\mathrm{C}$ & $\mathrm{G}$ & $\mathrm{T}$ & $\mathrm{T}$ & A & $\mathrm{T}$ & $\mathrm{T}$ & $\mathrm{C}$ & $\mathrm{T}$ & $\mathrm{C}$ & $\mathrm{C}$ \\
\hline $\mathrm{H} 2$ & 1 & - & $\bar{A}$ & - & - & - & - & - & - & - & - & - & - & - & - & - & - & - \\
\hline $\mathrm{H} 3$ & 14 & $\mathrm{C}$ & - & - & - & - & - & - & - & - & - & - & - & - & - & - & - & - \\
\hline $\mathrm{H} 4$ & 9 & - & - & - & - & - & - & - & - & - & - & - & $\mathrm{C}$ & - & - & - & - & - \\
\hline $\mathrm{H} 5$ & 1 & - & - & - & - & - & - & - & - & - & - & - & $\mathrm{C}$ & - & - & - & - & $\mathrm{T}$ \\
\hline $\mathrm{H} 6$ & 1 & - & - & - & - & - & - & - & - & - & - & $\mathrm{G}$ & - & - & - & - & - & - \\
\hline $\mathrm{H} 7$ & 2 & - & - & - & - & - & - & - & - & - & - & - & - & $\mathrm{C}$ & - & - & - & - \\
\hline $\mathrm{H} 8$ & 1 & - & - & - & - & - & - & - & - & - & - & - & - & - & $\mathrm{T}$ & - & - & - \\
\hline H9 & 3 & - & - & - & - & - & - & - & - & $\mathrm{C}$ & - & - & - & - & - & - & - & - \\
\hline H10 & 1 & - & - & - & - & - & - & - & - & - & - & - & - & - & - & - & $\mathrm{T}$ & - \\
\hline H11 & 1 & - & - & - & C & - & - & - & - & - & - & - & - & - & - & - & - & - \\
\hline H12 & 1 & - & - & - & - & - & - & - & $\mathrm{A}$ & - & - & - & - & - & - & - & - & - \\
\hline $\mathrm{H} 13$ & 1 & - & - & - & - & - & - & - & - & - & - & - & - & - & - & $\mathrm{C}$ & - & - \\
\hline H14 & 19 & - & - & - & - & - & - & $\mathrm{T}$ & $\mathrm{A}$ & - & $\mathrm{C}$ & - & - & - & - & $\mathrm{C}$ & - & - \\
\hline H15 & 2 & - & - & - & - & $\mathrm{C}$ & - & - & - & - & - & - & - & - & - & - & - & - \\
\hline H16 & 2 & - & - & $\mathrm{C}$ & - & - & $\mathrm{T}$ & - & - & - & - & - & - & - & - & - & - & - \\
\hline
\end{tabular}

We found that the number of haplotypes from different breeds varied from 1 to 6 , and haplotype diversity values from 0.356 in the HosZogdort to 0.889 in the Sunit Bactrian camel breed (Table 2). The Sunit Bactrian camel displayed the highest nucleotide diversity value (0.00115), whereas the HosZogdort breed had the lowest value (0.00031). When comparing $C y t b$ sequence variation in all Chinese domestic Bactrian camels with those of Mongolian and Russian domestic Bactrian camels, the level of diversity within China (nucleotide diversity: $0.00084)$ was higher than that of Russia (0.00068) and Mongolia (0.00060), whereas the level of haplotype diversity of China (0.679) was also higher than that of Russia (0.667) and Mongolia (0.582).

\section{Haplotype analysis of cytb sequences from domestic and wild Bactrian camels}

We found that the 16 different haplotypes were arranged into two haplogroups: the domestic Bactrian camel haplogroup and the wild Bactrian camel haplogroup (Figure 2). The domestic Bactrian camel haplogroup included 15 haplotypes, and the largest haplotype (H1) consisted of 52 individuals. There were three domesticated haplotype groups ( $\mathrm{H} 1, \mathrm{H} 3$, and H4) that included 9 or more individuals, and the other domesticated haplotypes contained fewer individuals. The main mitochondrial haplotypes (H1, H3, and H4) were shared between Chinese, Mongolian, and Russian domestic Bactrian camels, which indicated that there was little geographical structuring and apparent genetic admixture among the domestic breeds from the three regions. Moreover haplotypes specific to a geographic region were also discovered. For example, haplotypes H2, H5, H10-13, H15, and H16 were only found in Chinese domestic Bactrian camels; haplotypes H6, H7, and $\mathrm{H} 8$ were only found in Mongolian domestic Bactrian camels; but there were no specific haplotypes in Russian domestic Bactrian camels. In this study, all wild Bactrian camels consisted of only one haplotype (H14), in contrast to three haplotypes reported by a previous study (Ji et al., 2009b). Our results also suggest an extremely small effective population size of wild Bactrian camels, which are considered critically endangered by the International Union for Conservation of Nature.

Genetics and Molecular Research 15 (3): gmr.15038983 


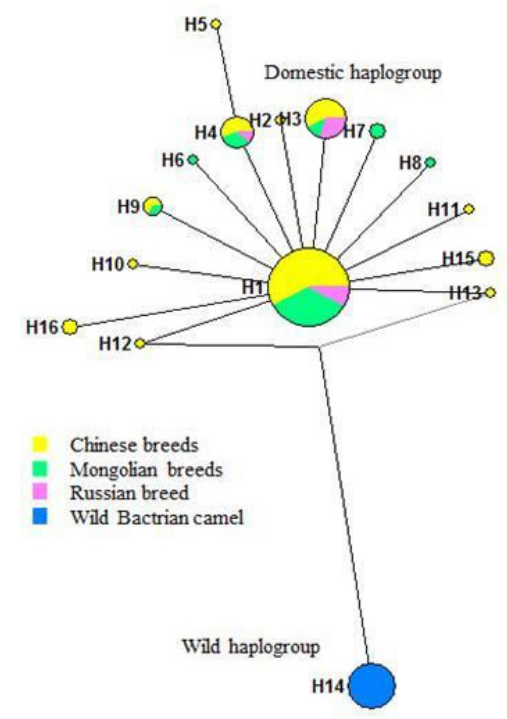

Figure 2. Median-joining network of $16 \mathrm{Cytb}$ haplotypes of domestic and wild Bactrian camels. The circled area is proportional to the frequency of the haplotype.

\section{Phylogenetic tree construction}

In this study, the UPGMA tree was constructed using 16 haplotypes of all Chinese, Mongolian, Russian domestic Bactrian camels and wild Bactrian camels, with the Dromedary camel (D. camelus) as the outgroup (GenBank accession No. X56281) (Figure 3). The phylogenetic tree clearly showed two major groups. The haplotype of the wild Bactrian camel (H14) formed one branch and is a sister group to a monophyletic lineage made up of all haplotypes of the domestic Bactrian camel. The results show that the extant wild Bactrian camel and domestic Bactrian camel form distinct mitochondrial lineages with independent maternal inheritance.

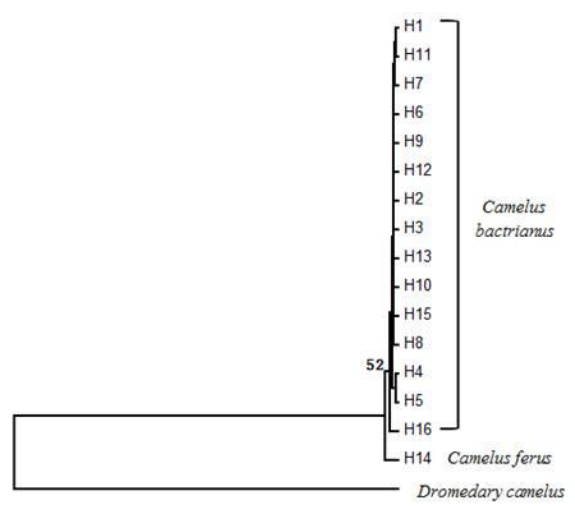

Figure 3. Unweighted Pair Group Method with Arithmetic Mean (UPGMA) phylogenetic tree of complete mitochondrial Bactrian camel cytb sequences showing the phylogenetic relationship of haplotypes (H1 to H16).

Genetics and Molecular Research 15 (3): gmr.15038983 


\section{DISCUSSION}

Molecular genetic analysis of mitochondrial (Jianlin et al., 2004; Ji et al., 2009b; Silbermmayr et al., 2010) and nuclear markers (Silbermmayr and Burger, 2012) provides estimates of the time of separation between wild and domestic Bactrian camels: 0.7-1.5 million years ago in the Pleistocene, which is much longer than the history of domestication. Archaeological research suggests that Bactrian camels migrated from North America through the Bering Strait, and then arrived in Asia about 3 million years ago (Harrison, 1985). Later, during the Pleistocene Epoch (1.8 million to 10000 years ago), Bactrian camel populations may have again been subdivided geographically, leading to a split of the two lineages (wild and domestic lineages) (Ji et al., 2009b). In this study, we found that 16 different haplotypes were divided into a domestic haplogroup and a wild haplogroup, and the phylogeographic analysis showed two major groups (wild and domestic Bactrian camel groups). This finding provides evidence that the extant wild Bactrian camel and domestic Bactrian camel carry distinct, maternally inherited mitochondrial lineages (Ji et al., 2009b).

In addition, there was no distinguishing geographic structuring of Cytb haplotypes among Mongolian, Chinese, and Russian domestic Bactrian camel breeds. This result is consistent with prior research, implying that domesticated Bactrian camels originated from a single maternal lineage (Ji et al., 2009b). In addition, strong gene flow existed among domestic Bactrian camel populations throughout history. For example, on the Silk Road, the merchants, pilgrims, soldiers, and nomads used a large population of domestic Bactrian camels to transport their goods and military supplies between different geographic areas in China, Russia, and Mongolia. Thus, it can be predicted domestic Bactrian camels frequently travelled between different geographic regions. Thus, the Silk Road could have led to the frequent hybridization and admixture of domestic Bactrian camels from different geographic regions.

A possible caveat of our study was that $C y t b$ sequence variation alone might not be sufficient to recover population genetic divergence in different geographic regions. Recently, the whole-genome sequence of the Bactrian camel was published (Ji et al., 2012). Future studies comparing whole-genome variation could be adopted for a more sophisticated investigation on the evolution and domestication of the Bactrian camel.

\section{ACKNOWLEDGMENTS}

Research supported by National International Scientific and Technological Cooperation Project \#2015DFR30680 and \#ky201401002, and Chinese National Natural Science Foundation Project \#31360397 and \#31360598.

\section{REFERENCES}

Atteson K (1999). The performance of the neighbor-joining methods of phylogenetic reconstruction. Algorithmica 25: 251-278. http://dx.doi.org/10.1007/PL00008277

Cheng J, Ren ZH, Wang L, Wang HL, et al. (2009). Molecular phylogeny of domestic bactrian camel revealed by partial cytochromeb gene. J. Northwest A \& F Univ. (Nat. Sci. Ed.). 37: 17-21.

Chuluunbat B, Charruau P, Silbermayr K, Khorloojav T, et al. (2014). Genetic diversity and population structure of Mongolian domestic Bactrian camels (Camelus bactrianus). Anim. Genet. 45: 550-558. http://dx.doi.org/10.1111/ age. 12158

Groeneveld LF, Lenstra JA, Eding H, Toro MA, et al.; GLOBALDIV Consortium (2010). Genetic diversity in farm 
animals - a review. Anim. Genet. 41 (Suppl 1): 6-31. http://dx.doi.org/10.1111/j.1365-2052.2010.02038.x

Harrison JA (1985). Giant camels from the Cenozoic of North America. Smithsonian Institution Press, Washington.

He XH, Han XL and Ma YH (2009). Progress in the study of genetic diversity of Bactrian camel. Acta Ecologiae Animalis Domastici 30: 9-13.

Ji R, Chen GL and Yun ZY (2009a). The bactrian camel and bactrian camel milk. 1st edn. Chinese Light Industry Press, Hohhot.

Ji R, Cui P, Ding F, Geng J, et al. (2009b). Monophyletic origin of domestic bactrian camel (Camelus bactrianus) and its evolutionary relationship with the extant wild camel (Camelus bactrianus ferus). Anim. Genet. 40: 377-382. http:// dx.doi.org/10.1111/j.1365-2052.2008.01848.x

Ji R, Wang Z, Ding G, Chen G, et al.; Bactrian Camels Genome Sequencing and Analysis Consortium (2012). Genome sequences of wild and domestic bactrian camels. Nat. Commun. 3: 1202. http://dx.doi.org/10.1038/ncomms2192

Jianlin H, Ochieng JW, Lkhagva B and Hanotte O (2004). Genetic diversity and relationship of domestic bactrian camels (Camelus bactrianus) in China and Mongolia. J. Camel Pract. Res. 11: 97-99.

Johns GC and Avise JC (1998). A comparative summary of genetic distances in the vertebrates from the mitochondrial cytochrome b gene. Mol. Biol. Evol. 15: 1481-1490. http://dx.doi.org/10.1093/oxfordjournals.molbev.a025875

Kumar S, Tamura K, Jakobsen IB and Nei M (2001). MEGA2: molecular evolutionary genetics analysis software. Bioinformatics 17: 1244-1245. http://dx.doi.org/10.1093/bioinformatics/17.12.1244

Li A, Zhao Q, Tang S, Zhang Z, et al. (2005). Molecular phylogeny of the domesticated silkworm, Bombyx mori, based on the sequences of mitochondrial cytochrome b genes. J. Genet. 84: 137-142. http://dx.doi.org/10.1007/BF02715839

Potts D (2005). Bactrian camels and Bactrian- dromedary hybrids. In: The silk road (D. Waugh, ed.). Silkroad Foundation, Saratoga. Available at [http://www.silkroadfoundation.org/newsletter/vol3num1/7_bactrian.php].

Quan JX, Zhang YP, Han JL and Men ZM (2000). Genetic diversity of mtDNA of domestic camels (C. bactrianus) in China. Yi Chuan Xue Bao 27: 383-390.

Rozas J, Sánchez-DelBarrio JC, Messeguer X and Rozas R (2003). DnaSP, DNA polymorphism analyses by the coalescent and other methods. Bioinformatics 19: 2496-2497. http://dx.doi.org/10.1093/bioinformatics/btg359

Schwartz HJ (1992). Productive performance and productivity of dromedaries (Camelus dromedarius). Anim Res Dev 35: 86-89.

Silbermmayr K and Burger PA (2012). Hybridization: A Threat to the genetic distinctiveness of the last wild Old World Camel species. In: Camels in Asia and North Africa (Knoll EM and Burger PA, eds.). Interdisciplinary Perspectives on their Significance in Past and Present. Austrian Acad. Sci. 69-76.

Silbermmayr K, Tero N, Charruau P, Enkhbileg D, et al. (2010). Isolation and characterization of nine new microsatellite loci in the domestic Bactrian camel (Camelus bactrianus) and amplification in the wild Bactrian camel (C. ferus). Mol. Ecol. Resour. 10: 1106-1108.

Sokal RR and Michener CD (1958). A statistical method for evaluating systematic relationships. Univ. Kans. Sci. Bull. 28: 1409-1438.

Thompson JD, Higgins DG and Gibson TJ (1994). CLUSTAL W: improving the sensitivity of progressive multiple sequence alignment through sequence weighting, position-specific gap penalties and weight matrix choice. Nucleic Acids Res. 22: 4673-4680. http://dx.doi.org/10.1093/nar/22.22.4673

Zhang Y, Zhang HB, Liu ZH and Wu M (2008). Molecular phylogeny of Altun Mountain wild Camelus bactrianus revealed by partial cytochromebgene sequences of mi-tochondrial DNA. J. Zhejiang Univ. 35: 87-91.

Zhong X, Wang N, Hu D, Wang J, et al. (2014). Sequence analysis of cytb gene in Echinococcus granulosus from Western China. Korean J. Parasitol. 52: 205-209. http://dx.doi.org/10.3347/kjp.2014.52.2.205

Genetics and Molecular Research 15 (3): gmr.15038983 